\title{
АКТИВНОСТЬ РАСТИТЕЛЬНОГО ПОКРОВА ПО СТРАНАМ
}

П.М. Мазуркин, С.И. Михайлова, kaf_po@mail.ru

Поволжский государственный технологический университет, Йошкар-Ола,

Аннотация На примере агроэкологического зонирования (AEZ) 160 стран по состоянию на 2002 г. рассмотрены 11 классов земельного покрова. Активность AEZ равна проценту от общей площади территории страны, а за объясняющую переменную принимается площадь каждого класса земельного покрова. Показаны пятичленные статистические модели распределений 160 стран по классам с волновыми составляющими с переменной амплитудой и периодом колебаний. По моделям выполнена проверка адекватности классификации земельного покрова по классам. Предложен AEZ «растительный покров», содержащий группу из трех первых классов земельного покрова.

Ключевые слова: земельный покров, классы, проверка классификации, растительный покров, 160 стран, распределения, закономерности.

\section{ACTIVITY OF THE VEGETABLE COVER OVER THE COUNTRIES P.M. Mazurkin, S.I. Michajlova \\ Volga State University of Technology, Yoshkar-Ola, Russia, kaf_po@mail.ru}

Abstract. On the example of agro-ecological zoning (AEZ) of 160 countries as of 2002 11 classes of a land cover are considered. Activity of AEZ is equal to percent from the total area of the territory of the country, and the area of each class of a land cover is accepted to explaining variable. Five-membered statistical models of distributions of 160 countries on classes with wave components with a variable amplitude and the period of fluctuations are shown. On models check of adequacy of classification of a land cover on classes is executed. AEZ «vegetable cover» containing group of the three first classes of a land cover is offered.

Keywords: land cover, classes, classification check, vegetable cover, 160 countries, distributions, regularities.

Введение. Среди глобальных агроэкологических зон важное место занимает растительный покров. Чтобы соединить нашу методологию геотриадного подхода «территория + население + хозяйство» [3] с известными в мире классами земельного покрова [1] в статье привели статистические модели по массиву исходных данных data15.xls.

Наибольшую активность распространения и интенсивность воспроизводства имеет травяной покров $[2,4,7,13]$. Гораздо сложнее функциональные связи в лесолуговом фитоценозе [9]. Выявленные закономерности позволили идентифицировать модели кадастровой стоимости сельхозугодий [5], дать методики оценки негативного воздействия промышленных объектов на окружающую среду [6], оценки риска продуктивности сенокосов и пастбищ [7], прогнозирования продуктивности сельскохозяйственных угодий [8]. Эти работы позволили разработать методологию территориального экологического равновесия [11] и оценивать нерациональность природопользования [10, 12, 14].

Исходные данные. Массив data15.xls (табл. 1) содержит значения площади $S_{R}$ $\left(10^{3}\right.$ га) по 11 (Olson классификация GLCC, версия 1.2) классам земельного покрова 160 стран по рангу $R$ этого класса: 0 - Grass-land (травяной покров); 1 - Wood-land (древесно-кустарниковая растительность, ДКР); 2 - Forest (лес); 3 - Mosaics incl. AGR. (мозаика с включением сельхозугодий, CXУ); 4 - Mosaics dom. AGR. (мозаика с доминированием $\mathrm{CXY);} 5$ - Crop land (земли для растениеводства, пашни); 6 - Wet-land (мокрые, увлажненные земли); 7 - Desert, barren (пустыня, бесплодная); 8 - Water, coast (вода, побережье); 9 - Ce, cold desert (Лед, холодная пустыня); 10 - Urban (городская территория). 
Доля от общей площади страны в процентах в каждом классе земельного покрова становится показателем, а абсциссу нужно будет вначале выбирать.

Пространственный график, дающий картину влияния общей площади $S$ территории стран на удельные доли каждого класса земельного покрова, дан на рисунке 1 .

Таблица 1. Распространение совокупности почвенно-растительного покрова по классам

\begin{tabular}{|c|c|c|c|c|c|c|c|c|c|c|c|c|}
\hline \multirow{3}{*}{$\begin{array}{c}\text { Наименование } \\
\text { страны }\end{array}$} & \multirow{3}{*}{$\begin{array}{l}\text { Площадь } \\
S, 10^{3} \text { га }\end{array}$} & \multicolumn{11}{|c|}{ Доля (активность) класса земельного покрова по рангам, \% } \\
\hline & & \multicolumn{5}{|c|}{ растительный покров } & \multicolumn{6}{|c|}{ земельный покров без растительности } \\
\hline & & $\alpha_{0}$ & $\alpha_{1}$ & $\alpha_{2}$ & $\alpha_{3}$ & $\alpha_{4}$ & $\alpha_{5}$ & $\alpha_{6}$ & $\alpha_{7}$ & $\alpha_{8}$ & $\alpha_{9}$ & $\alpha_{10}$ \\
\hline $\mathrm{CA}$ & & 0.5 & 15.5 & 31 & 3.9 & 2.8 & 0.1 & 2.2 & 4.6 & 10.4 & 28.4 & 0.0 \\
\hline UNI & & 13.7 & 2 & 26 & 13 & & 9 & 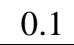 & 13 & & .4 & 0.8 \\
\hline & & & 5 & 24.3 & 22.9 & 48 & 0.6 & 0.0 & & & 0.0 & 0.8 \\
\hline BEI & & & 0. & 3 & 69.8 & 25.4 & 0.0 & 0.0 & .0 & 0 & 0.0 & 0.4 \\
\hline HUNGARY & 9213 & 0.0 & 1.6 & 9.0 & 15.1 & 70.3 & 0.3 & 0.0 & 0.0 & 2.1 & 0.0 & 1.6 \\
\hline & & & & & & & & & & & & \\
\hline
\end{tabular}

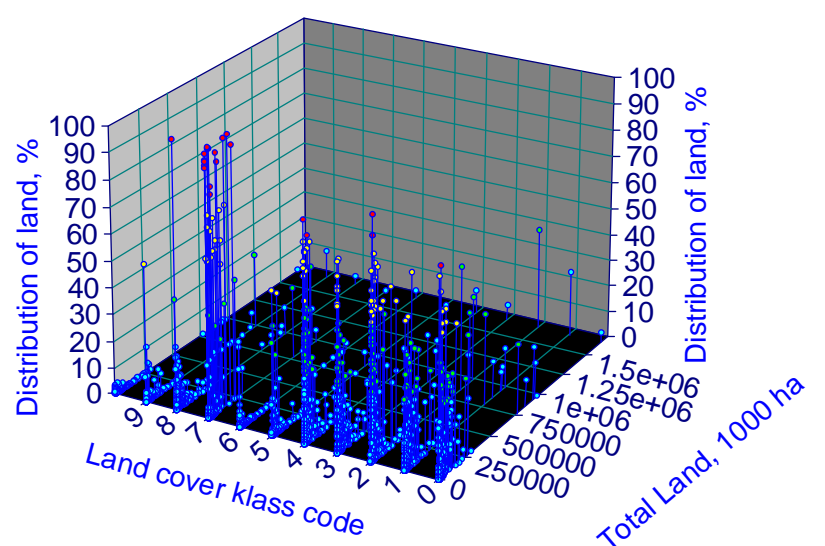

Рис. 1. Распределение доли классов земельного покрова по общей площади стран и рангам классов
Моделирование показало, что коэффициенты корреляции равны менее 0,3. Поэтому адекватность моделей зависимости активности $\alpha_{R}$ от изменения площади территории страны $S$ очень низкая. В итоге не существует закономерности типа $\alpha_{R}=f(S)$.

Территория страны по площади не влияет на активность классов земельного покрова. Однако на уровне муниципалитетов субъекта РФ были сильные закономерности $\alpha_{R}=f(S)$ с корреляцией более $0,7[11,14]$.

Травяной покров. Подробно рассмотрим (рис. 2) пятичленную зависимость $\alpha_{0}=f\left(S_{0}\right)$, значения параметров которого приведены в таблице 2.

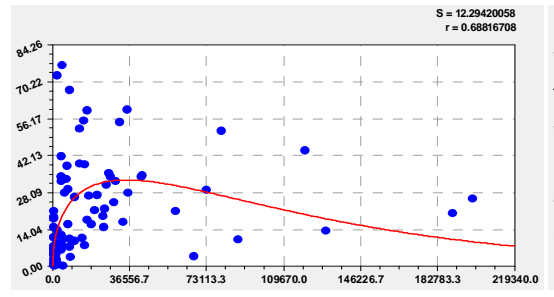

первая составляющая

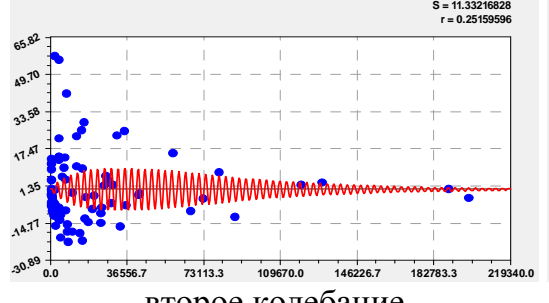

второе колебание

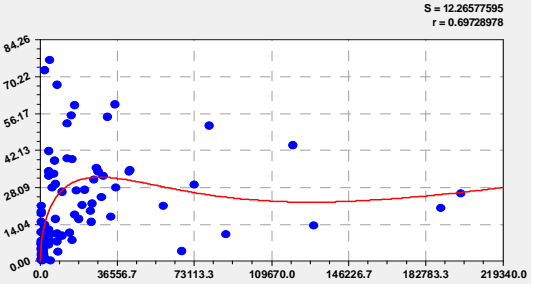

двухчленный тренд

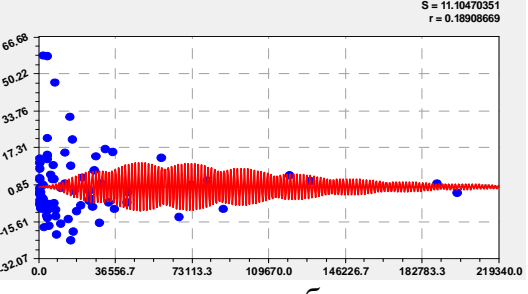

третье колебание

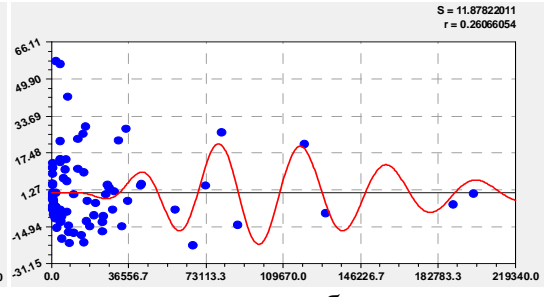

первое колебание

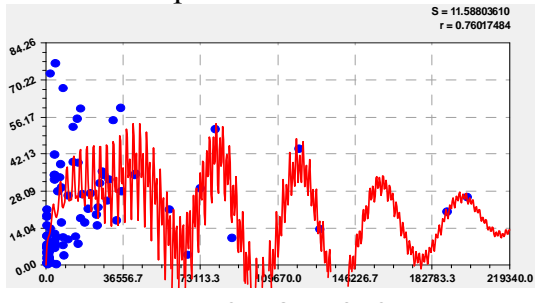

пятичленная модель (в верхнем правом углу графиков: $S$ - дисперсия; $r$ - коэффициент корреляции)

Формула с параметрами из таблицы 2 для травы относится к сильным связям.

Другие классы растительного покрова. По другим четырем классам графики пятичленных уравнений с параметрами модели по таблице 2 приведены на рисунке 3.

Из пяти классов земельного покрова по доле площади от общей площади территории 160 стран в зависимости от площади данного класса наибольшую адекватность получила древесно-кустарниковая растительность. 
На втором месте находится лесной покров, а на третьем - травяной покров.

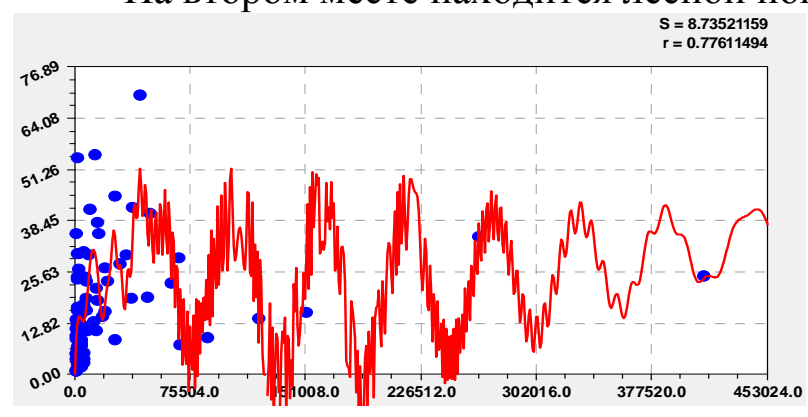

древесно-кустарниковая растительность

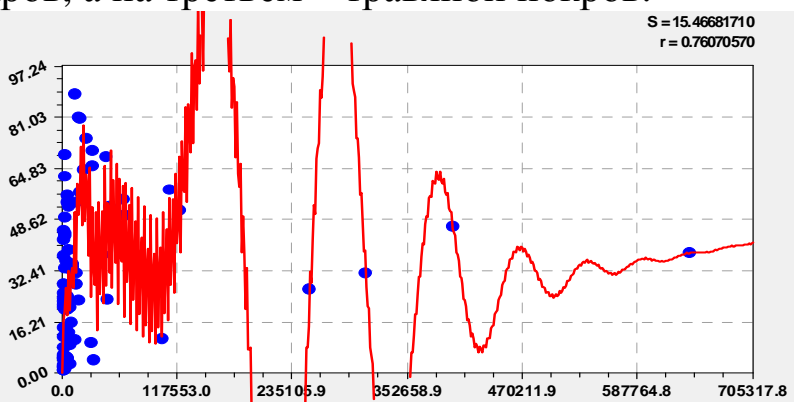

$S=12.11541676$

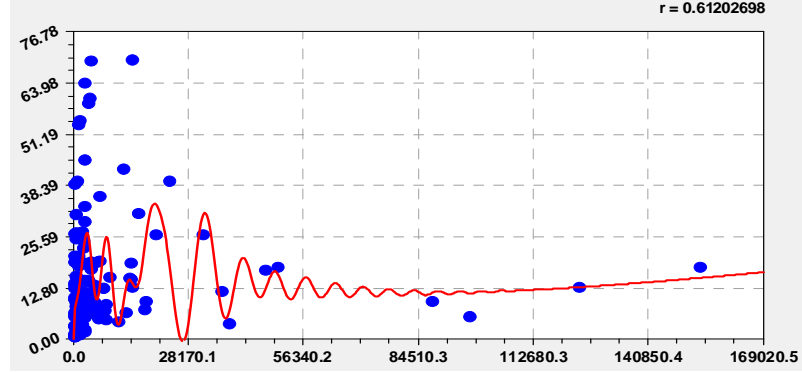

мозаичный покров с включением СХУ

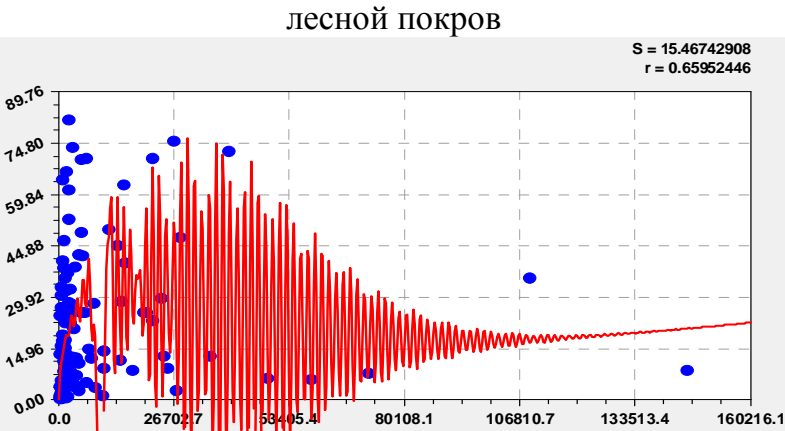

мозаика с доминированием СХУ

Рис. 3. Графики моделей распределения 160 стран по классам растительного земельного покрова

Среднюю адекватность 0,6120 получил «мозаичный покров с включением СХУ».

Таблица 2. Параметры вейвлет-сигналов активности растительного покрова по классам

\begin{tabular}{|c|c|c|c|c|c|c|c|c|c|}
\hline \multirow{3}{*}{$\begin{array}{c}\text { № } \\
i\end{array}$} & \multicolumn{8}{|c|}{ Вейвлет $\alpha_{R}=a_{1 i} S_{R}{ }^{a_{2 i}} \exp \left(-a_{3 i} S_{R}{ }^{{ }^{4}}{ }^{4 i}\right) \cos \left(\pi S_{R} /\left(a_{5 i}+a_{6 i} S_{R}{ }^{{ }^{2}}\right)-a_{8 i}\right)$} & \multirow{3}{*}{$\begin{array}{c}\text { Коэфф } \\
\text { коррел. } \\
r\end{array}$} \\
\hline & \multicolumn{4}{|c|}{ Амплитуда колебания } & \multicolumn{4}{|c|}{ Полупериод и сдвиг колебания } & \\
\hline & $a_{1 i}$ & $\overline{a_{2 i}}$ & $a_{3 i}$ & $\bar{a} a_{4 i}$ & $\overline{a a_{5 i}}$ & $a_{6 i}$ & $a_{7 i}$ & $a_{8 i}$ & \\
\hline \multicolumn{10}{|c|}{0 - Grass-land (травяной покров) } \\
\hline 1 & 0,26904 & 0,53366 & $2,27368 \mathrm{e}-5$ & 1,01074 & 0 & 0 & 0 & 0 & \multirow{5}{*}{0,7602} \\
\hline 2 & $2,18016 \mathrm{e}-7$ & 1,48278 & 0 & 0 & 0 & 0 & 0 & 0 & \\
\hline 3 & $1,56917 \mathrm{e}-16$ & 3,76511 & $4,00000 \mathrm{e}-5$ & 0,99331 & 19669,710 & $\mid-0,00076914$ & 1,03894 & 0,46100 & \\
\hline 4 & 0,0041448 & 0,84079 & $4,00270 \mathrm{e}-5$ & 0,96307 & 1597,7128 & 0 & 0 & 0,24114 & \\
\hline 5 & $4,66327 \mathrm{e}-7$ & 1,71933 & $3,99994 \mathrm{e}-5$ & 0,97605 & 787,12845 & 0 & 0 & 1,19288 & \\
\hline \multicolumn{10}{|c|}{1 - Wood-land (древесно-кустарниковая растительность, ДКР) } \\
\hline 1 & 0,25230 & 0,51385 & $5,70339 \mathrm{e}-5$ & 0,90195 & 0 & 0 & 0 & 0 & \multirow{5}{*}{0,7761} \\
\hline 2 & 0,00028356 & 0,89873 & $1,94238 \mathrm{e}-20$ & 1 & 0 & 0 & 0 & 0 & \\
\hline 3 & $3,88297 \mathrm{e}-9$ & 2,05087 & $3,00000 \mathrm{e}-5$ & 0,95157 & 3380,2331 & $-0,017120$ & 1,01504 & 2,61803 & \\
\hline 4 & 0,018837 & 0,68683 & $3,00000 \mathrm{e}-5$ & 1 & 5331,2591 & 0,038591 & 1 & 0,10407 & \\
\hline 5 & $7,01763 \mathrm{e}-6$ & 1,38463 & $3,99431 \mathrm{e}-5$ & 0,88749 & 28112,603 & 0 & 0 & $-0,84683$ & \\
\hline \multicolumn{10}{|c|}{2 - Forest (лес, лесной покров) } \\
\hline 1 & 1,06579 & 0,38793 & $1,00000 \mathrm{e}-5$ & 0,99860 & 0 & 0 & 0 & 0 & \multirow{5}{*}{0,7607} \\
\hline 2 & $5,55121 \mathrm{e}-5$ & 1,00353 & $8,37575 \mathrm{e}-31$ & 1 & 0 & 0 & 0 & 0 & \\
\hline 3 & $6,40402 \mathrm{e}-31$ & 6,58704 & $3,00000 \mathrm{e}-5$ & 1,00029 & 99128,234 & $-0,081794$ & 1,00013 & $-0,84126$ & \\
\hline 4 & $-3,43531 \mathrm{e}-9$ & 2,49192 & $3,00000 \mathrm{e}-5$ & 1,13028 & 16511,869 & 0 & 0 & 0,72961 & \\
\hline 5 & 1513,6080 & 0,85471 & $4,00000 \mathrm{e}-5$ & 0,91282 & 1513,6080 & 0,00049231 & 0,98753 & 0,88911 & \\
\hline \multicolumn{10}{|c|}{3 - Mosaics incl. AGR. (мозаика с включением сельхозугодий, СХУ) } \\
\hline 1 & 1,29556 & 0,31613 & $2,49801 \mathrm{e}-5$ & 1,01402 & 0 & 0 & 0 & 0 & \multirow{5}{*}{0,6120} \\
\hline 2 & $3,05710 \mathrm{e}-5$ & 1,09604 & 0 & 0 & 0 & 0 & 0 & 0 & \\
\hline 3 & 0,00081709 & 1,10045 & $7,24242 \mathrm{e}-5$ & 0,99690 & 5557,0713 & $-0,020451$ & 0,98919 & 1,89247 & \\
\hline 4 & $1,50137 \mathrm{e}-17$ & 4,71654 & $9,25934 \mathrm{e}-5$ & 1,09626 & 75,34102 & $1,02638 \mathrm{e}-7$ & 1 & $-2,70546$ & \\
\hline 5 & $9,62579 \mathrm{e}-7$ & 2,09816 & 0,00033345 & 1 & 37,60758 & $-1,16287 \mathrm{e}-7$ & 1 & $-3,04615$ & \\
\hline \multicolumn{10}{|c|}{4 - Mosaics dom. AGR. (мозаика с доминированием СХУ) } \\
\hline 1 & 0,55798 & 0,47437 & $3,80866 \mathrm{e}-5$ & 0,99468 & 0 & 0 & 0 & 0 & \multirow{5}{*}{0,6595} \\
\hline 2 & 0,00012951 & 1,00506 & $3,42804 \mathrm{e}-9$ & 1 & 0 & 0 & 0 & 0 & \\
\hline 3 & $7,06675 \mathrm{e}-78$ & 22,25764 & 0,0023575 & 1 & 21860,515 & $-1,37373$ & 1 & 0,40769 & \\
\hline 4 & $8,36405 \mathrm{e}-17$ & 4,26118 & 0,00011031 & 1,00056 & 817,41583 & 0 & 0 & $-1,56785$ & \\
\hline 5 & $9,17121 \mathrm{e}-6$ & & $8,71976 \mathrm{e}-5$ & 0,98932 & 24,99553 & 0 & 0 & $-1,02812$ & \\
\hline
\end{tabular}


Земли для растениеводства (пашни). Этот класс земельного покрова является чисто антропогенным явлением на планете Земля (рис. 4).
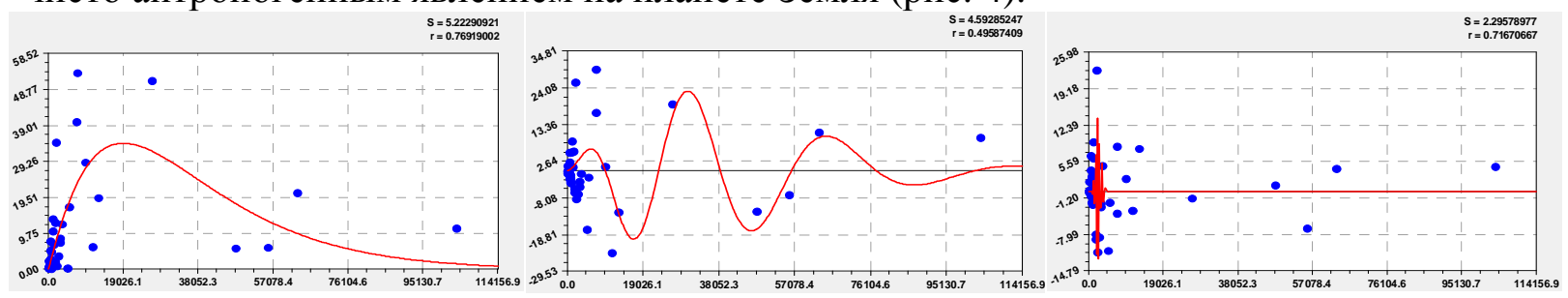

первая составляющая (тренд)
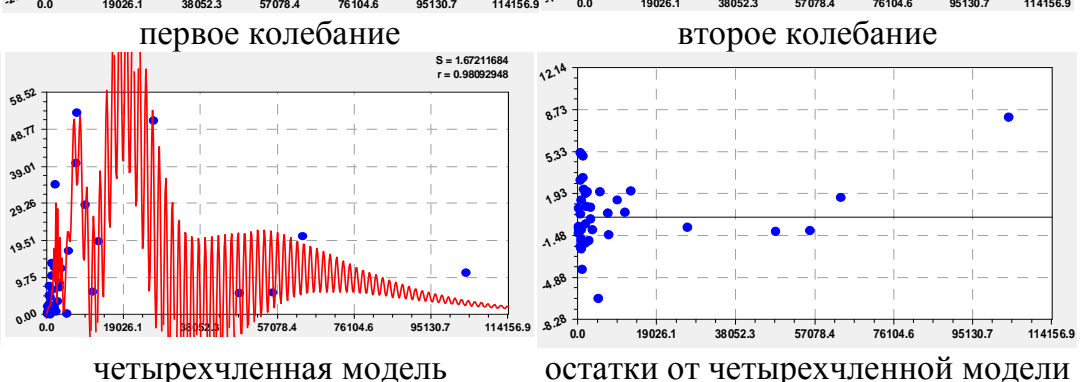
третье колебание четырехчленная модель остатки от четырехчленной модели Рис. 4. Графики составляющих модели распределения 160 стран по пашням

Параметры модели для пашни приведены в таблице 3.

Земельный покров без растительности. По всем шести классам графики пятичленных уравнений с параметрами модели по таблице 3 приведены на рисунке 5.
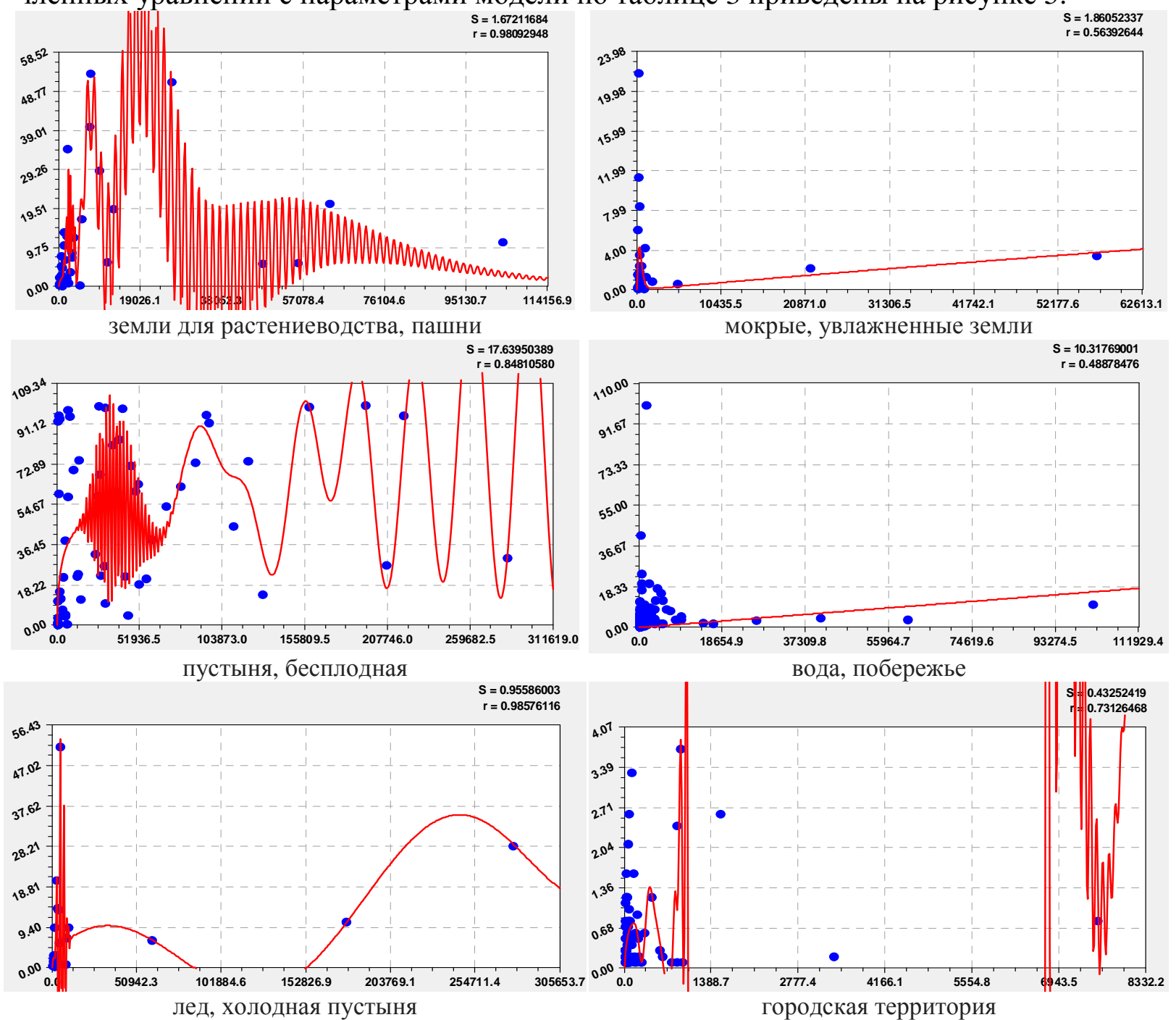

Рис. 5. Графики моделей распределения 160 стран по классам земельного покрова без растительности

Графики показывают, что недостаточно точны распределения по классам 6 и 8. 
Таблица 3. Параметры вейвлетов активности земельного покрова без растительности по классам

\begin{tabular}{|c|c|c|c|c|c|c|c|c|c|}
\hline \multirow{3}{*}{$\begin{array}{c}\text { № } \\
i\end{array}$} & \multicolumn{8}{|c|}{ Вейвлет $\alpha_{R}=a_{1 i} S_{R}^{a_{2 i}} \exp \left(-a_{3 i} S_{R}^{a_{4 i}}\right) \cos \left(\pi S_{R} /\left(a_{5 i}+a_{6 i} S_{R}^{a_{7 i}}\right)-a_{8 i}\right)$} & \multirow{3}{*}{$\begin{array}{c}\text { Коэфф } \\
\text { коррел } \\
r\end{array}$} \\
\hline & \multicolumn{4}{|c|}{ Амплитуда колебания } & \multicolumn{4}{|c|}{ Полупериод и сдвиг колебания } & \\
\hline & $a_{1 i}$ & $a_{2 i}$ & $a_{3 i}$ & $a_{4 i}$ & $a_{5 i}$ & $a_{6 i}$ & $a_{7 i}$ & $a_{8 i}$ & \\
\hline \multicolumn{10}{|c|}{5 - Crop land (земли для растениеводства, пашни) } \\
\hline 1 & 0,0076080 & 0,96181 & $4,35368 \mathrm{e}-5$ & 1,02446 & 0 & 0 & 0 & 0 & \multirow{4}{*}{0,9809} \\
\hline 3 & $-0,00094669$ & 1,15390 & $3,96009 \mathrm{e}-5$ & 1,02935 & 1151,1767 & 0,10373 & 1,01380 & 1,82131 & \\
\hline 4 & $-6,05767 e-38$ & 12,97656 & 0,0041214 & 1,02913 & 339,07009 & $-0,035879$ & 0,97904 & $-2,68923$ & \\
\hline 5 & $1,27755 \mathrm{e}-6$ & 1,86100 & $7,96933 \mathrm{e}-5$ & 1 & 24,96630 & 0 & 0 & 0,64976 & \\
\hline \multicolumn{10}{|c|}{6 - Wet-land (мокрые, увлажненные земли) } \\
\hline 1 & 0,00059279 & 2,03957 & 0,030508 & 0,78812 & 0 & 0 & 0 & 0 & \multirow{2}{*}{0,5639} \\
\hline 2 & $7,79830 \mathrm{e}-5$ & 0,99148 & $1,22273 \mathrm{e}-6$ & 1 & 0 & 0 & 0 & 0 & \\
\hline \multicolumn{10}{|c|}{7 - Desert, barren (пустыня, бесплодная) } \\
\hline 1 & $4,56699 \mathrm{e}-7$ & 2,41892 & 20,79502 & 0,060256 & 0 & 0 & 0 & 0 & \multirow{5}{*}{0,8481} \\
\hline 2 & $6,26190 \mathrm{e}-5$ & 1,07083 & $1,39713 \mathrm{e}-15$ & 1 & 0 & 0 & 0 & 0 & \\
\hline 3 & $4,33368 \mathrm{e}-14$ & 3,22424 & $3,00000 \mathrm{e}-5$ & 1,00003 & 29999,193 & 0,030212 & 1,00469 & 2,59752 & \\
\hline 4 & $-3,44971 e-18$ & 3,76237 & $1,00000 \mathrm{e}-5$ & 0,99692 & 17061,983 & 0,0010232 & 1,04239 & 0,40178 & \\
\hline 5 & 4,51972e-39 & 9,74557 & 0,00027889 & 1,00048 & 985,95479 & 0,0013660 & 0,99935 & 0,45316 & \\
\hline \multicolumn{10}{|c|}{8 - Water, coast (вода, побережье) } \\
\hline 1 & 0,00015796 & 1 & 0 & 0 & 0 & 0 & 0 & 0 & 0,4888 \\
\hline \multicolumn{10}{|c|}{9 - Ce, cold desert (лед, холодная пустыня) } \\
\hline 1 & 0,19147 & 0,38053 & 0 & 0 & 0 & 0 & 0 & 0 & \multirow{4}{*}{0,9858} \\
\hline 3 & $-9,44245 \mathrm{e}-38$ & 11,74386 & 0,0022155 & 1 & 397,35303 & $-0,0029241$ & 0,99346 & 0,60710 & \\
\hline 4 & $-1,61666 \mathrm{e}-22$ & 7,20373 & 0,0018526 & 0,98035 & 1967,6406 & $-0,094590$ & 0,99719 & $-4,57638$ & \\
\hline 5 & $3.87116 \mathrm{e}-8$ & 1,88183 & $3,00000 \mathrm{e}-5$ & 0,94320 & 244654,1 & $-0,65020$ & 0,95485 & $-1,14847$ & \\
\hline \multicolumn{10}{|c|}{10 - Urban (городская территория) } \\
\hline 1 & 0,047485 & 0,66734 & 0,0041399 & 1 & 0 & 0 & 0 & 0 & \multirow{5}{*}{0,7313} \\
\hline 2 & 0,00010535 & 1,22234 & 0 & 0 & 0 & 0 & 0 & 0 & \\
\hline 3 & $1,07046 \mathrm{e}-11$ & 3,96667 & 0,0014319 & 0,97292 & 192,52015 & 0,030796 & 0,98620 & 0,43797 & \\
\hline 4 & $5,25852 \mathrm{e}-49$ & 17.08215 & 0,0014319 & 1,03125 & 48,33261 & $6,93315 e-5$ & 1,00101 & 1,38908 & \\
\hline 5 & $2,75864 \mathrm{e}-44$ & 21,02961 & 0,065005 & 0,99984 & 490,36702 & $-0,42574$ & 1,00046 & $-1,70156$ & \\
\hline
\end{tabular}

Земельный покров под водой получил только одну составляющую по линейной модели. На первом месте по адекватности стоит ледяной покров, а на втором - пашни.

Активность растительного покрова. Дополнительно к классам земельного покрова (табл. 4) были введены три группировки растительного покрова:

РП0 - растительный покров с объединением рангов $0+1+2$, то есть суммарная доля травяного покрова, ДКР и леса [11], поэтому РП0 $=\alpha_{0}+\alpha_{1}+\alpha_{2}$;

РП1 - дополнительно к РПО учитывается доля с рангом 3 мозаики с включением СХУ (сельскохозяйственных угодий), поэтому РП1 $=\alpha_{0}+\alpha_{1}+\alpha_{2}+\alpha_{3}$;

РП2 - дополнительно к РП1 учитывается доля с рангом 4 мозаики с доминированием СХУ, поэтому РП $2=\alpha_{0}+\alpha_{1}+\alpha_{2}+\alpha_{3}+\alpha_{4}$.

Таблица 4. Группы классов растительного покрова (фрагмент)

\begin{tabular}{|c|c|c|c|c|c|c|c|c|c|c|}
\hline \multirow{2}{*}{$\begin{array}{c}\text { Наименование } \\
\text { страны }\end{array}$} & \multirow{2}{*}{$\begin{array}{c}\text { Площадь } \\
S, 10^{3} \text { га }\end{array}$} & \multicolumn{3}{|c|}{ Доля группы РП, \% } & \multicolumn{3}{|c|}{ Площадь РП, $10^{3}$ га } & \multicolumn{3}{|c|}{ Активность РП } \\
\hline & & РП0 & РП1 & РП2 & $S_{P I 00}$ & $S_{P \Pi 1}$ & $S_{P \Pi 2}$ & $\beta_{0}$ & $\beta_{1}$ & $\beta_{2}$ \\
\hline CANADA & 978404 & 47.7 & 51.6 & 54.4 & 466699 & 504856 & 532252 & 0.477 & 0.516 & 0.544 \\
\hline UNITED STATES & 946837 & 49.6 & 62.7 & 68.9 & 469631 & 593667 & 652371 & 0.496 & 0.627 & 0.689 \\
\hline BULGARIA & 11057 & 25.1 & 48.0 & 96.8 & 2775 & 5307 & 10703 & 0.251 & 0.480 & 0.968 \\
\hline BELARUS & 20615 & 3.5 & 73.3 & 98.7 & 722 & 15111 & 20347 & 0.035 & 0.733 & 0.987 \\
\hline HUNGARY & 9213 & 10.6 & 25.7 & 96.0 & 977 & 2368 & 8844 & 0.106 & 0.257 & 0.960 \\
\hline & $\ldots$ & 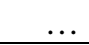 & & & .. & & & & & \\
\hline
\end{tabular}

Графики даны на рисунке 6, а значения параметров моделей в таблице 4.

Растительным покровом в действительности является только РП0. Дополнение мозаиками с включением или доминированием СХУ дает меньшую адекватность. 
РПО $\beta_{0}=\left(\alpha_{0}+\alpha_{1}+\alpha_{2}\right) / 100$

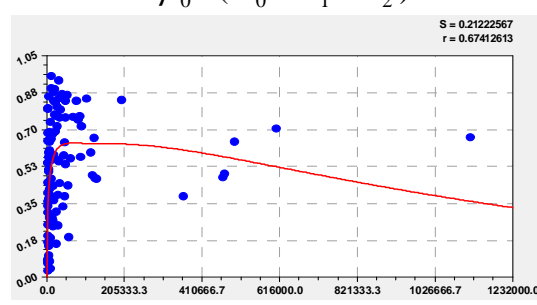

двухчленный тренд

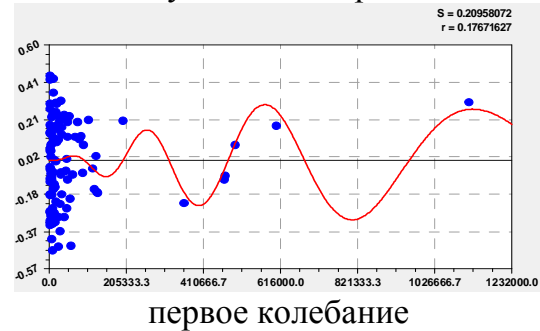

первое колебание

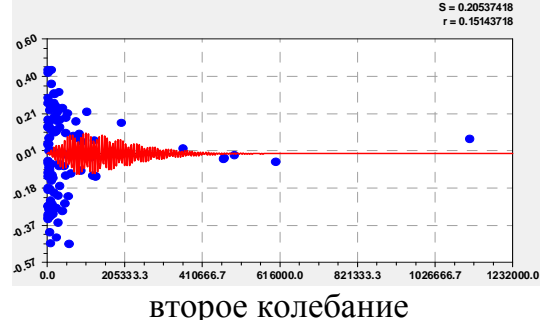

второе колебание

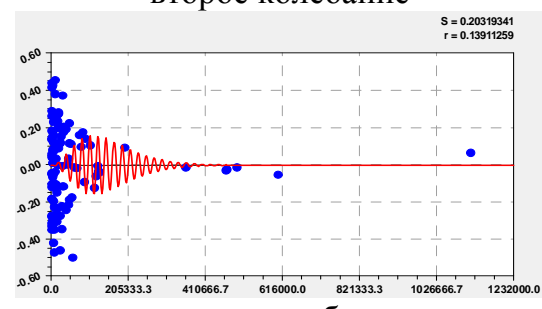

третье колебание

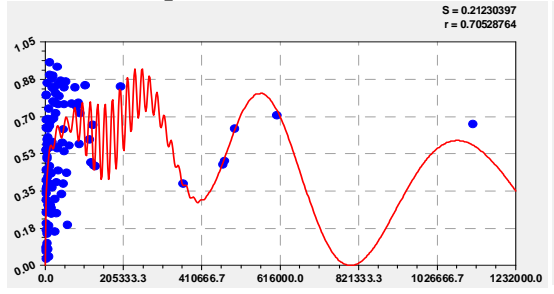

пятичленная модель

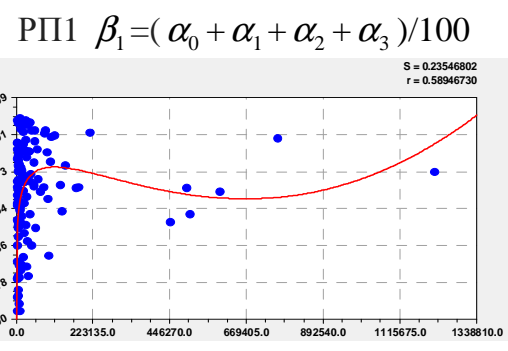

двухчленный тренд

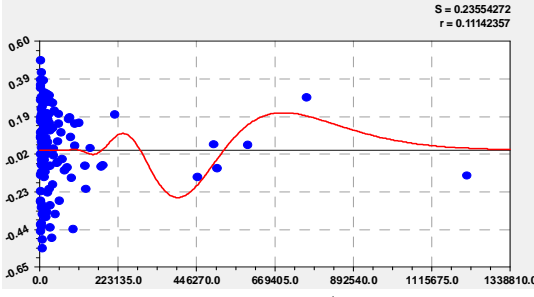

первое колебание

$S=0202090908$
$r=0.20033131$

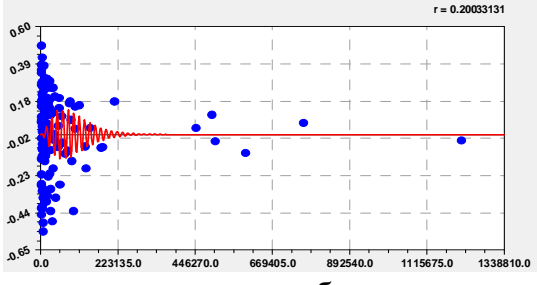

второе колебание

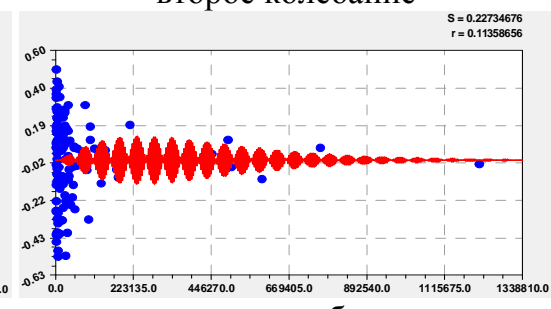

третье колебание

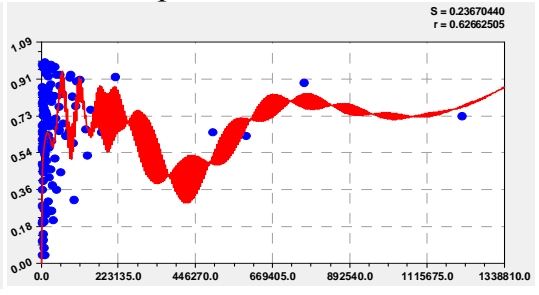

пятичленная модель
$\mathrm{P}$ 2 $\beta_{2}=\left(\alpha_{0}+\alpha_{1}+\alpha_{2}+\alpha_{3}+\alpha_{4}\right) / 100$

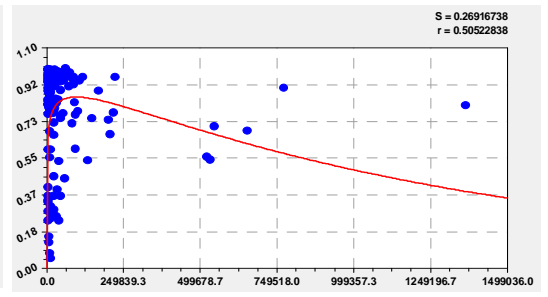

первый член

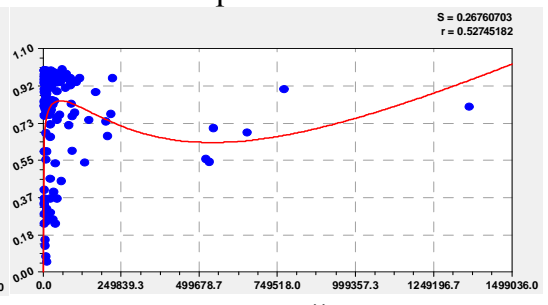

двухчленный тренд

Малая волна с коэффициентом корреляции 0,0640

Нет волны возмущения

Нет волны возмущения

Рис. 6. Графики моделей распределения 160 стран по трем группам растительного покрова

Таблица 4. Параметры вейвлетов активности растительного покрова по группам классов

\begin{tabular}{|c|c|c|c|c|c|c|c|c|c|}
\hline \multirow{3}{*}{$\begin{array}{c}\text { № } \\
i\end{array}$} & \multicolumn{8}{|c|}{ Вейвлет $\beta=a_{1 i} S_{P \Pi}^{a_{2 i}} \exp \left(-a_{3 i} S_{P \Pi}{ }^{a_{4 i}}\right) \cos \left(\pi S_{P \Pi} /\left(a_{5 i}+a_{6 i} S_{P \Pi}{ }^{a_{7 i}}\right)-a_{8 i}\right)$} & \multirow{3}{*}{$\begin{array}{c}\text { Коэфф } \\
\text { коррел } \\
r\end{array}$} \\
\hline & \multicolumn{4}{|c|}{ Амплитуда колебания } & \multicolumn{4}{|c|}{ Полупериод и сдвиг колебания } & \\
\hline & $a_{1 i}$ & $a_{2 i}$ & $a_{3 i}$ & $a_{4 i}$ & $a_{5 i}$ & $a_{6 i}$ & $a_{7 i}$ & $a_{8 i}$ & \\
\hline \multicolumn{10}{|c|}{ РП0 - растительный покров с суммой рангов $0+1+2$} \\
\hline 1 & 0,0028739 & 0,44628 & $7,67365 \mathrm{e}-5$ & 0,95457 & 0 & 0 & 0 & 0 & \multirow{5}{*}{0,7052} \\
\hline 2 & 0,025498 & 0,30489 & $1,38849 \mathrm{e}-5$ & 0,85166 & 0 & 0 & 0 & 0 & \\
\hline 3 & $1,98995 \mathrm{e}-9$ & 1,50620 & $1,00000 \mathrm{e}-6$ & 1,04357 & 76781,436 & 0,073228 & 1,00735 & 1,94295 & \\
\hline 4 & $-5,87437 \mathrm{e}-7$ & 1,15277 & $1,00000 \mathrm{e}-5$ & 1,02380 & 50,00010 & 0 & 0 & 0,57527 & \\
\hline 5 & $5,68629 \mathrm{e}-14$ & 2,69783 & $2,00000 \mathrm{e}-5$ & 1,00869 & 1245,9781 & 0 & 0 & 0,71445 & \\
\hline \multicolumn{10}{|c|}{ РП1 - к РП0 + доля с рангом 3 мозаики с включением СХУ } \\
\hline 1 & 0,11234 & 0,18379 & $1,08003 \mathrm{e}-5$ & 0,86533 & 0 & 0 & 0 & 0 & \multirow{5}{*}{0,6266} \\
\hline 2 & $3,36894 \mathrm{e}-17$ & 2,66075 & 0 & 0 & 0 & 0 & 0 & 0 & \\
\hline 3 & $1,71461 \mathrm{e}-28$ & 5,10273 & $2,00000 \mathrm{e}-5$ & 0,93596 & 13395,973 & 0,091240 & 1,01423 & 5,78859 & \\
\hline 4 & $1,52328 \mathrm{e}-10$ & 2,07665 & $7,00000 \mathrm{e}-5$ & 0,93494 & 99,77961 & 0 & 0 & 0,49979 & \\
\hline 5 & $-6,00977 \mathrm{e}-9$ & 1,50453 & $2,00000 \mathrm{e}-5$ & 0,91210 & 795,78441 & 0 & 0 & 1,97991 & \\
\hline
\end{tabular}

Примечание. Параметры модели РП2, из-за низкой адекватности, не приведены. 
Влияние рангов классов и их групп земельного покрова. Сводные данные приведены в таблице 5. По мере роста ранга $R$ коэффициент корреляции $r$ изменяется.

Таблица 5. Коэффициенты корреляции модели по рангам классов земельного покрова

\begin{tabular}{|c|c|c|c|c|c|}
\hline \multirow{2}{*}{$\begin{array}{c}\text { Распределение классов } \\
\text { земельного покрова по рангам }\end{array}$} & \multicolumn{5}{|c|}{ Количество членов в модели } \\
\hline & 1 & 2 & 3 & 4 & 5 \\
\hline \multicolumn{6}{|c|}{ По 11 классам земельного покрова } \\
\hline 0. Grass-land (травяной покров) & 0,6882 & 0,6973 & 0,7270 & 0,7484 & 0,7602 \\
\hline 1. Wood-land (древесно-кустарни & 0,4531 & 0,7142 & 0,7397 & 0,7477 & 0,7761 \\
\hline 2. Forest (лес, лесной покров) & 0,6674 & 0,6820 & 0,6892 & 0,7209 & 0,7607 \\
\hline 3. Mosaics incl. AGR. (мозаика с вкл. сельхозугодий) & 0,4324 & 0,4418 & 0,5034 & 0,5587 & 0,6120 \\
\hline 4. Mosaics dom. AGR. (мозаика с доминированием CXУ) & 0,4799 & 0,4918 & 0,5406 & 0,6302 & 0,6560 \\
\hline 5. Crop land (земли для растениеводства, пашни) ${ }^{1}$ & 0,7692 & 0,7692 & 0,9172 & 0,9644 & 0,9809 \\
\hline 6. Wet-land (мокрые, увлажненные земли) ${ }^{2}$ & 0,5444 & 0,5639 & 0,5639 & 0,5639 & 0,5639 \\
\hline 7. Desert, barren (пустыня, бесплодная) & 0,7568 & 0,7571 & 0,7833 & 0,8055 & 0,8481 \\
\hline 8. Water, coast ( вода, побережье) ${ }^{3}$ & 0,4888 & 0,4888 & 0,4888 & 0,4888 & 0,4888 \\
\hline 9. Ce, cold desert (Лед, холодная пустыня) ${ }^{1}$ & 0,6271 & 0,6271 & 0,8534 & 0,9701 & 0,9858 \\
\hline 10. Urban (городская территория) & 0,5275 & 0,5275 & 0,6344 & 0,7196 & 0,7313 \\
\hline \multicolumn{6}{|c|}{ По группам классов растительного покрова } \\
\hline РП0 - растительный покров с суммой рангов $0+1+2$ & 0,5473 & 0,6741 & 0,6881 & 0,6975 & 0,7053 \\
\hline РП1 - к РП + доля с рангом 3 мозаики с включ. СХУ & 0,5778 & 0,5895 & 0,5982 & 0,6194 & 0,6266 \\
\hline РП2 - к РП1 + доля с рангом 4 мозаики с домин. СХУ & 0,5052 & 0,5275 & 0,5275 & 0,5275 & 0,5275 \\
\hline
\end{tabular}

Примечания. ${ }^{1}$ Без второй составляющей. ${ }^{2}$ Без трех волн. ${ }^{3}$ Только первый член.

После идентификации по 11 рангам классов земельного покрова были получены статистические модели (рис. 7, табл. 6):

- один член биотехнической закономерности

$$
\begin{gathered}
r_{1}=0,69115 \exp (-0,53415 R)+0,11407 R^{1,27282} \exp \left(-0,030679 R^{1,65942}\right)- \\
\quad-6,69576 R^{4,49810} \exp \left(-2,22721 R^{0,81388}\right) \cos (\pi R / 1,01270-4,57496) ;
\end{gathered}
$$

- два члена биотехнической закономерности

$$
\begin{aligned}
& r_{2}=0,72634 \exp (-0,10426 R)+0,00059951 R^{7,81387} \exp \left(-1,89986 R^{0,79803}\right)- \\
& -2,17558 \cdot 10^{7} R^{14,74889} \exp \left(-19,38527 R^{0,43637}\right) \cos (\pi R / 1,00769-4,62458) ;
\end{aligned}
$$

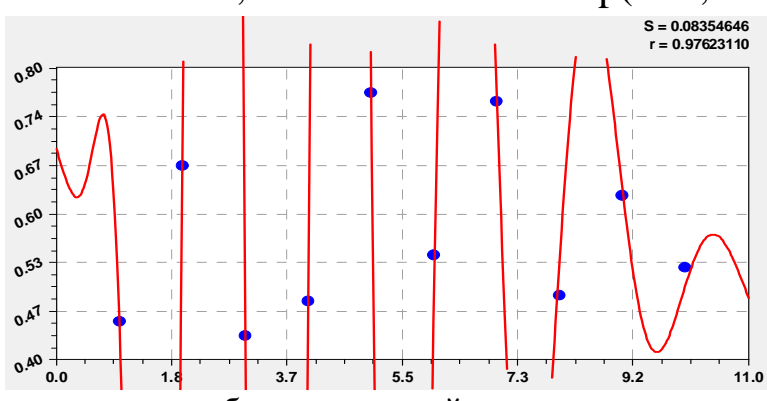

один член биотехнической закономерности
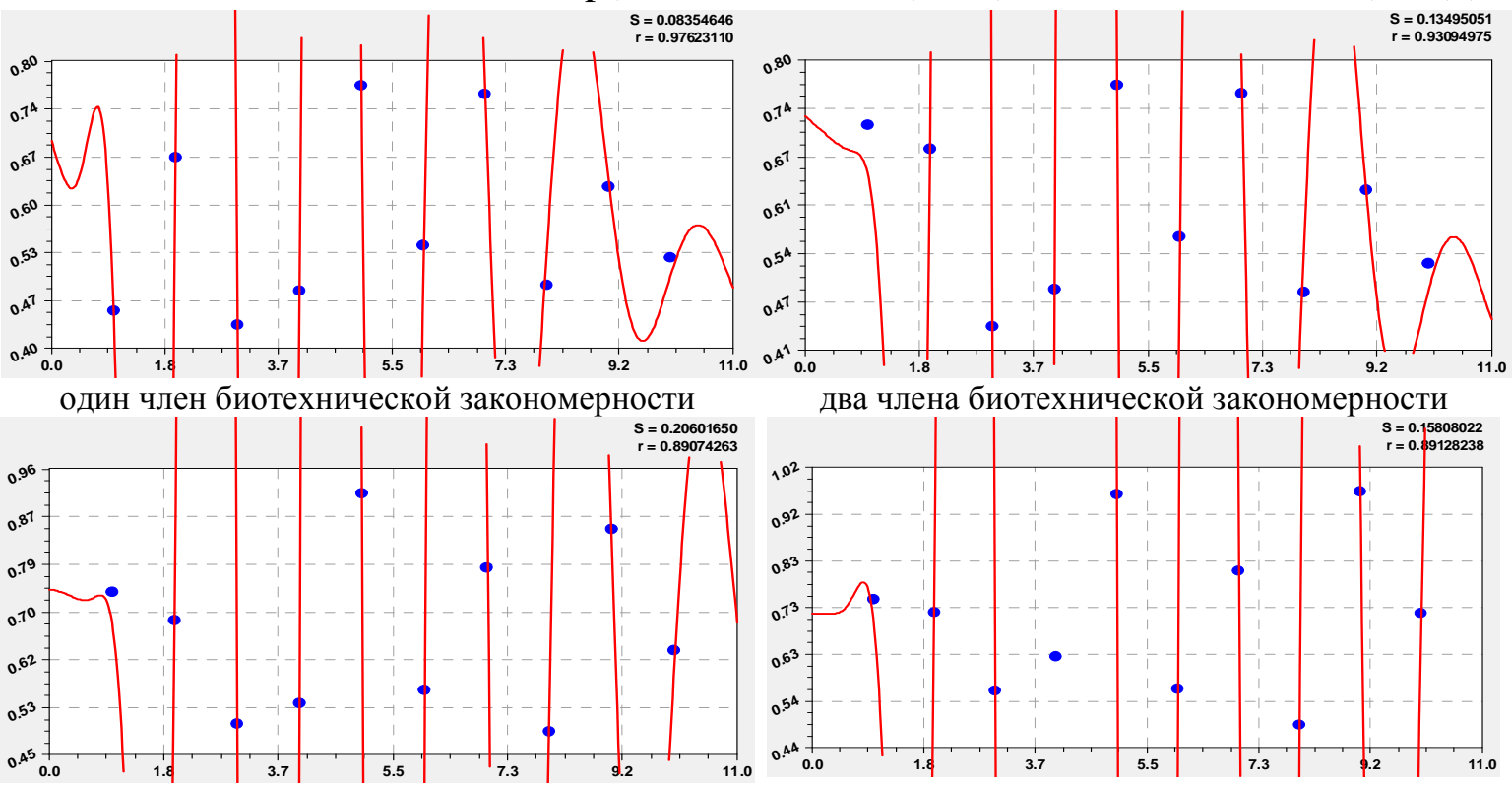

два члена биотехнической закономерности

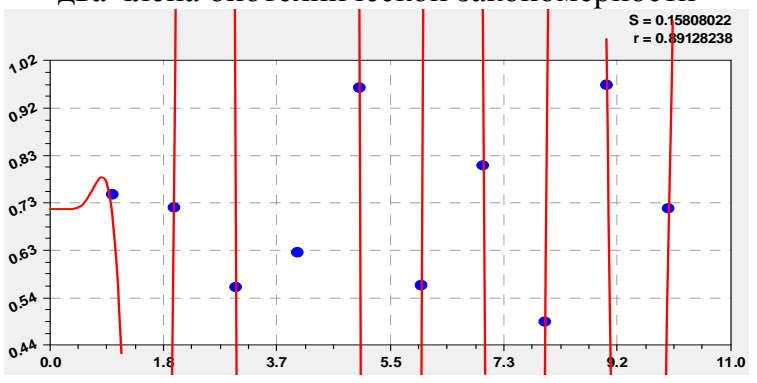

четыре члена биотехнической закономерности

три члена биотехнической закономерности

Рис. 7. Графики влияния рангов уровней земельных ограничений на адекватность модели

- три члена биотехнической закономерности

$$
\begin{aligned}
r_{3} & =0,74328 \exp \left(-0,090671 R^{1,58101}\right)+0,019614 R^{3,23506} \exp \left(-0,51748 R^{0,88161}\right)- \\
& -2,55539 \cdot 10^{8} R^{13,40925} \exp \left(-21,01933 R^{0,38255}\right) \cos (\pi R / 1,00486-4,65918) ;
\end{aligned}
$$


- четыре члена биотехнической закономерности

$$
\begin{gathered}
r_{4}=0,71725 \exp \left(-0,0036236 R^{1,36244}\right)+1,23438 \cdot 10^{-8} R^{7,19202}- \\
-3,57602 \cdot 10^{6} R^{10,80257} \exp \left(-16,18172 R^{0,38497}\right) \cos (\pi R / 1,00302-4,67840) ;
\end{gathered}
$$

\begin{tabular}{|c|c|c|c|c|c|c|c|c|c|}
\hline \multirow{3}{*}{$\begin{array}{c}\text { № } \\
i\end{array}$} & \multicolumn{8}{|c|}{ Вейвлет $r=a_{1 i} R^{a_{2 i}} \exp \left(-a_{3 i} R^{a_{4 i}}\right) \cos \left(\pi R /\left(a_{5 i}+a_{6 i} R^{a_{7 i}}\right)-a_{8 i}\right)$} & \multirow{3}{*}{$\begin{array}{c}\text { Коэфф. } \\
\text { коррел. } \\
\quad r\end{array}$} \\
\hline & \multicolumn{4}{|c|}{ Амплитуда колебания } & \multicolumn{4}{|c|}{ Полупериод и сдвиг колебания } & \\
\hline & $a_{1 i}$ & $a_{2 i}$ & $a_{3 i}$ & $a_{4 i}$ & $a_{5 i}$ & $a_{6 i}$ & $a_{7 i}$ & $a_{8 i}$ & \\
\hline \multicolumn{10}{|c|}{ Один член в модели классификации } \\
\hline 1 & 0,69114 & 0 & 0,53415 & 1 & 0 & 0 & 0 & 0 & \multirow{3}{*}{0,9762} \\
\hline 2 & 0,11407 & 1,27282 & 0,030679 & 1,65942 & 0 & 0 & 0 & 0 & \\
\hline 3 & $-6,69576$ & 4,49810 & 2,22721 & 0,81388 & 1,01270 & 0 & 0 & 4,57496 & \\
\hline \multicolumn{10}{|c|}{ Два члена в модели классификации } \\
\hline 1 & 0,72634 & 0 & 0,10426 & 1 & 0 & 0 & 0 & 0 & \multirow{3}{*}{0,9309} \\
\hline 2 & 0,00059991 & 7,81387 & 1,89986 & 0,79803 & 0 & 0 & 0 & 0 & \\
\hline 3 & $-2,17658 \mathrm{e} 7$ & 14,74829 & 19,38527 & 0,43637 & 1,00769 & 0 & 0 & 4,62458 & \\
\hline \multicolumn{10}{|c|}{ Три члена в модели классификации } \\
\hline 1 & 0,74328 & 0 & 0,090671 & 1,58101 & 0 & 0 & 0 & 0 & \multirow{3}{*}{0,8907} \\
\hline 2 & 0,019614 & 3,23506 & 0,51748 & 0,88161 & 0 & 0 & 0 & 0 & \\
\hline 3 & $-2,55539 \mathrm{e} 8$ & 13,40925 & 21,01933 & 0,38255 & 1,00486 & 0 & 0 & 4,65918 & \\
\hline \multicolumn{10}{|c|}{ Четыре члена в модели классификации } \\
\hline 1 & 0,71725 & 0 & 0,0036236 & 1,36244 & 0 & 0 & 0 & 0 & \multirow{3}{*}{0,8913} \\
\hline 2 & $1,23438 \mathrm{e} 8$ & 7,19202 & 0 & 0 & 0 & 0 & 0 & 0 & \\
\hline 3 & $-3,57602 \mathrm{e} 6$ & 10,80257 & 16,18172 & 0,38497 & 1,00302 & 0 & 0 & 4,67840 & \\
\hline \multicolumn{10}{|c|}{ Пять членов в модели классификации } \\
\hline 1 & 0,76395 & 0 & 0,011186 & 1,04819 & 0 & 0 & 0 & 0 & \multirow{4}{*}{0,9999} \\
\hline 2 & $4,28243 e-9$ & 7,65468 & 0 & 0 & 0 & 0 & 0 & 0 & \\
\hline 3 & $-1,08848 \mathrm{e} 5$ & 10,87895 & 13,83442 & 0,41990 & 1,00487 & 0 & 0 & 4,65877 & \\
\hline 4 & 0,035284 & 0,83225 & 0,00012017 & 4,28798 & 3,02368 & $-0,057993$ & 1,17628 & 0,12679 & \\
\hline
\end{tabular}

Таблица 6. Параметры вейвлетов коэффициентов корреляции по 11 классам земельного покрова

Высокая адекватность формул (коэффициент корреляции выше 0,89) позволяет утверждать о добротности распределения земель планеты по 11 классам земель.

Проверка классификации земельных классов. По модели из пяти членов (табл. 5) покажем методику оценки добротности для системы классификации земельного покрова по 11 классам (рис. 8, табл. 6).
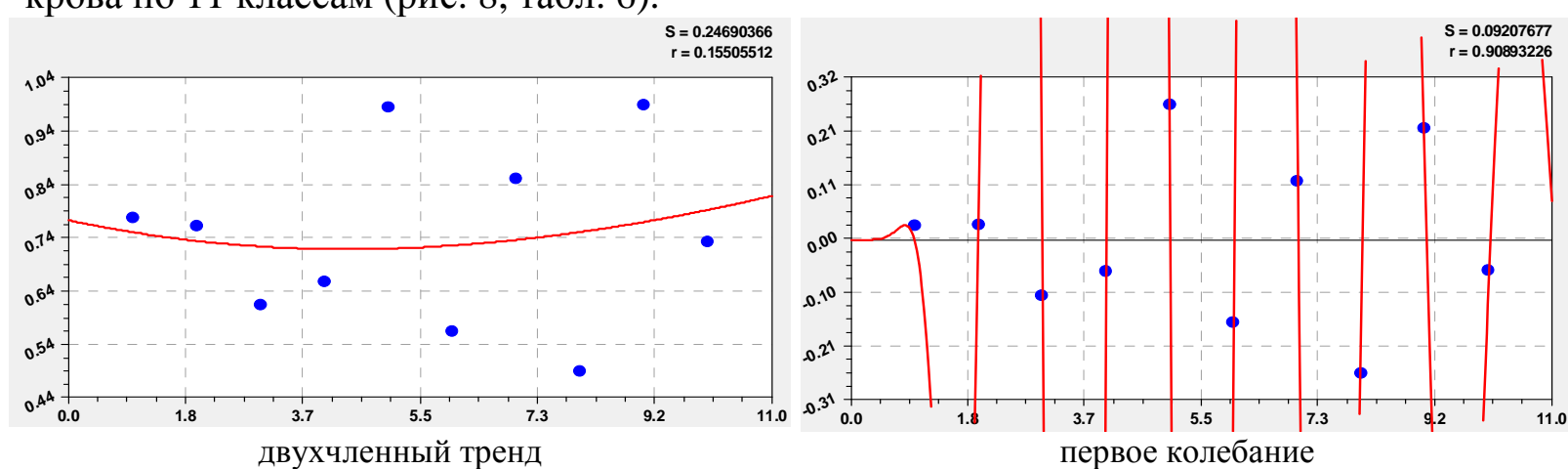
двухчленный тренд первое колебание
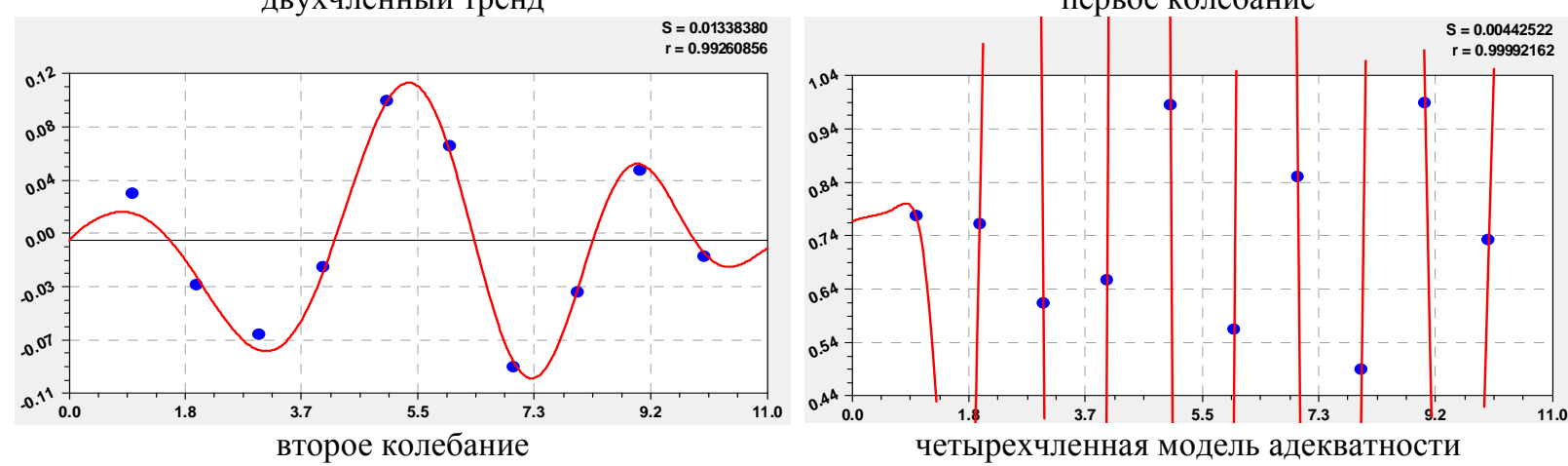

Рис. 8. Графики влияния рангов классов земельного покрова на адекватность модели из пяти членов 
После идентификации была получена (рис. 8) четырехчленная формула

$$
\begin{gathered}
r_{5}=0,76395 \exp \left(-0,011186 R^{1,04819}\right)+4,28243 \cdot 10^{-9} R^{7,65468}- \\
-A_{1} \cos \left(\pi R / p_{1}-4,65877\right)+A_{2} \cos \left(\pi R / p_{2}-0,12679\right), \\
A_{1}=1,08848 \cdot 10^{5} R^{10,87895} \exp \left(-13,83442 R^{0,41990}\right), p_{1}=1,00487, \\
A_{2}=0,035284 R^{0,83225} \exp \left(-0,00012017 R^{4,28798}\right), p_{2}=3,02368-0,057993 R^{1,17628},
\end{gathered}
$$

где $A_{1}, A_{2}$ - амплитуда (половина) колебательного возмущения системы классов,

$p_{1}, p_{2}$ - полупериод колебания среди рангов классификации земельного покрова у 160 стран по классам.

Коэффициент корреляции 0,9999 показывает добротность классификации 160 стран на 11 классов по земельному покрову мира.

Коэффициент приспособляемости $k$ системы к внешней среде показывает возможности её адаптивной устойчивости к волновым возмущениям.

Этот оценочный показатель исчисляется по формуле

$$
k_{i>1}=y_{i>1} / y_{1},
$$

где $y_{1}$ - первая трендовая закономерность, в формуле (6) первый член модели, показывающий спад корреляции с возрастанием ранга класса земельного покрова.

В нашем примере $k=\left(\hat{r}_{5}-r_{51}\right) / r_{51}$, где $\hat{r}_{5}$ - фактические значения коэффициента корреляции по данным таблицы 5 , а $r_{51}=0,76395 \exp \left(-0,011186 R^{1,04819}\right)$ по формуле (6). Результаты расчетов даны в таблице 7.

Для характеристики приспособляемости системы можно принять аналогию с поведением водителя машины на дороге. Водитель постоянно приспосабливается своим поведением, а также поведением управляемой им машины, к дороге и быстро меняющейся ситуации на ней.

Представим как машину планету Земля, ускоренно развивающуюся, зачем-то и куда-то устремленную. Двигателем быстрых изменений биосферы и движения Земли, как показал В.И. Вернадский, является человечество со своей технической сферой. Насколько этот двигатель будет усовершенствован, чтобы не терять при различных экологических изменениях скорость движения до пределов роста и устойчивого развития, настолько будет устойчивым развитие системы «человечество + биосфера».

В конечном итоге необходима нормализация процесса развития земельного покрова для достижения устойчивости системы человечества.

Таблица 7. Коэффициенты приспособляемости и динамичности 11 классов земельного покрова

\begin{tabular}{|c|c|c|c|c|c|}
\hline $\begin{array}{c}\text { Ранг } \\
R\end{array}$ & $\begin{array}{c}\text { Коэффициент } \\
\text { корреляции } \hat{r}_{5}\end{array}$ & $\begin{array}{c}\text { Первый } \\
\text { член }(6)\end{array}$ & $\begin{array}{c}\text { Коэффициент } \\
\text { приспособляемости } k\end{array}$ & $\begin{array}{c}\text { Второй } \\
\text { член (6) }\end{array}$ & $\begin{array}{c}\text { Коэффициент } \\
\text { динамичности } K_{\partial}\end{array}$ \\
\hline 0 & 0,7602 & 0,7640 & $-0,0049$ & 0,0000 & $-0,0049$ \\
\hline 1 & 0,7761 & 0,7555 & 0,0273 & 0,0000 & 0,0273 \\
\hline 2 & 0,7607 & 0,7465 & 0,0190 & 0,0000 & 0,0190 \\
\hline 3 & 0,6120 & 0,7374 & $-0,1700$ & 0,0000 & $-0,1701$ \\
\hline 4 & 0,6560 & 0,7283 & $-0,0992$ & 0,0002 & $-0,0994$ \\
\hline 5 & 0,9809 & 0,7191 & 0,3640 & 0,0010 & $\mathbf{0 , 3 6 2 2}$ \\
\hline 6 & 0,5639 & 0,7100 & $-0,2058$ & 0,0039 & $-0,2101$ \\
\hline 7 & 0,8481 & 0,7010 & 0,2098 & 0,0126 & 0,1885 \\
\hline 8 & 0,4888 & 0,6920 & $-0,2936$ & 0,0350 & $-0,3277$ \\
\hline 9 & 0,9858 & 0,6831 & $\mathbf{0 , 4 4 3 2}$ & 0,0863 & 0,2813 \\
\hline 10 & 0,7313 & 0,6742 & 0,0847 & 0,1934 & $-0,1571$ \\
\hline
\end{tabular}

Наибольший коэффициент приспособляемости имеет ледяной покров Земли.

Коэффициент динамичности $K_{\partial}$ системы, который показывает устойчивость функционирования системы в данный момент «среза» времени в динамике значений изучаемого показателя.

Указанный критерий оценки вычисляется по соотношению 


$$
K_{\partial i}=\left(\sum_{i \geq 2 \vee 3}^{m} y_{i}+\varepsilon\right) / y_{m p},
$$

где $y_{m p}$ - тренд, состоящий из нескольких первых не волновых составляющих из общей статистической модели, $\varepsilon$ - абсолютная погрешность (остатки) модели.

Если в тренде содержится два не волновых члена, формула (8) приводится для нашего примера (табл. 7) к виду $K_{\partial}=\left(\hat{r}_{5}-r_{51}-r_{52}\right) /\left(r_{51}+r_{52}\right)$.

Из данных таблицы 7 видно, что наибольший коэффициент динамичности наблюдается у пашни (часть земельного покрова для растениеводства).

Заключение. Для оценки земельных ресурсов мира, как показало статистическое моделирование, классы земельного покрова составляют добротную систему классификации. При этом за влияющую переменную принимается не площадь территории страны, а площадь каждого класса земельного покрова. Зависимой переменной (показателем) становится доля этого класса в общей площади территории страны.

Кроме классов земельного покрова, нами предлагается учитывать растительный покров, содержащий три первых класса земельного покрова (травяной покров + древесно-кустарниковая растительность + лесной покров). Как показало статистическое моделирование, дополнение в состав растительного покрова мозаичного покрова с включением сельхозугодий значительно снижает адекватность статистических моделей распределения 160 стран. А дальнейшее включение еще и мозаичного покрова с доминированием сельхозугодий еще больше снижает коэффициент корреляции.

\section{Литература}

1. Global Agro-ecological Assessment for Agriculture in the 21st Century: Methodology and Results. $G \ddot{u}$ ther Fischer, Harrij van Velthuizen, Mahendra Shah, Freddy Nachtergaele. International Institute for Applied Systems Analysis, Laxenburg, Austria. Food and Agriculture Organization of the United Nations. Viale delle Terme di Caracalla. Rome, Italy, 2002. Url: http://webarchive.iiasa.ac.at/Research/LUC/SAEZ/index.html.

2. Мазуркин П.М., Михайлова С.И. Биотехническая оценка пойменного луга. М.: Изд-во «Академия естествознания», 2009. 279 с.

3. Мазуркин П.М., Михайлова С.И. Геотриадное измерение сельских территорий // Международный журнал прикладных и фундаментальных исследований. 2009. № 4. С.28-35.

4. Мазуркин П.М., Михайлова С.И. Измерение активности растительного покрова // Международный журнал прикладных и фундаментальных исследований. 2009. № 4. С.36-45.

5. Мазуркин П.М., Михайлова С.И. Модели кадастровой оценки сельхозугодий // АПК: Экономика и управление. 2009. № 8. С.76-82.

6. Мазуркин П.М., Михайлова С.И. Оценка негативного воздействия промышленных объектов на окружающую среду по площади растительного покрова // Экология и промышленность России. 2009. Июль. С.46-48.

7. Мазуркин П.М., Михайлова С.И. Оценка риска продуктивности сенокосов и пастбищ // Основы рационального природопользования. Матер. II междунар. науч.-практ. конф. Саратов: Изд. центр «Наука», 2009. С.226-242.

8. Мазуркин П.М., Михайлова С.И. Прогнозирование продуктивности сельскохозяйственных угодий // Успехи современного естествознания. 2010. № 1. С. 149-153.

9. Мазуркин П.М., Михайлова С.И. Распределение растительной массы в лесолуговом фитоценозе // Вестник УМО по образованию в области природообустройста и водопользоваия. 2011. № 3. С. 330-340.

10. Мазуркин П.М., Михайлова С.И. Теоретические подходы к рационализации природопользования // Сб. статей «Наука в условиях современности». Йошкар-Ола: МарГТУ, 2006. С.276-282.

11. Мазуркин П. М., Михайлова С.И. Территориальное экологическое равновесие = Territprial ecological balance: аналит. обзор; Учреждение Рос. акад. наук Гос. публич. науч.-техн. б-ка Сиб. отд-ния РАН, Марийс. гос. техн. ун-т. Новосибирск : ГПНТБ СО РАН, 2010. 430 с. (Сер. Экология. Вып. 94).

12. Михайлова С.И., Мазуркин П.М. Закономерность перехода категорий эрозии почв // Защита и обустройство природной среды: сб. статей школьников и студентов, бакалавров и магистров, асп. и мол. ученых. Йошкар-Ола, МарГТУ, 2005. С. 87.

13. Михайлова С.И., Мазуркин П.М. Ландшафтно-экологическая роль пойменного луга малых рек. Йошкар-Ола: МарГТУ, 2011. 154 с.

14. Михайлова С.И., Мазуркин П.М. Рациональное землепользование в Кировской области // Защита и обустройство природной среды: сб. статей школьников и студентов, бакалавров и магистров, асп. и мол. ученых. ЙошкарОла, МарГТУ, 2005. С. 70-73. 